\title{
MONITORAMENTO DA QUALIDADE DA ÁGUA E AVALIAÇÃO DA CAPACIDADE DE AUTODEPURAÇÃO DO RIO LIGEIRO NO MUNICÍPIO DE PATO BRANCO - PR
}

\author{
MONITORING OF WATER QUALITY AND EVALUATION OF THE SELF-PURIFICATION \\ CAPACITY OF THE LIGEIRO RIVER IN THE MUNICIPALITY OF PATO BRANCO- PR
}

\author{
Ezequias da LUZ ${ }^{1}$, Julio Caetano TOMAZONI ${ }^{1}$, Ticiane Sauer POKRYWIECKI ${ }^{2}$ \\ ${ }^{1}$ Programa de Pós-Graduação em Engenharia Civil da Universidade Tecnológica Federal do Paraná (UTFPR), Pato Branco, PR, \\ Brasil.E-mail: ezequias.luz@ hotmail.com; caetano@utfpr.edu.br \\ ${ }^{2}$ Programa de Pós-Graduação de Engenharia Ambiental (PPGEA) - Universidade Tecnológica Federal do Paraná (UTFPR), \\ Francisco Beltrão, PR, Brasil. E-mail: ticiane@utfpr.edu.br

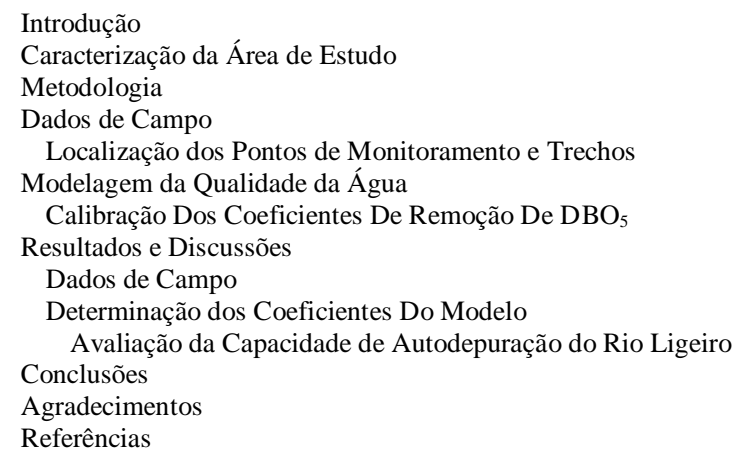

RESUMO - Este estudo teve como objetivo realizar o monitoramento da qualidade da água para a avaliação da capacidade de autodepuração do Rio Ligeiro, desde uma das nascentes até a confluência com o Rio Chopim. Estabeleceram-se seis pontos de monitoramento (PM01 a PM06) ao longo do percurso. Foram realizadas coletas de amostras de água nas diferentes estações do ano de 2017, para análises de oxigênio dissolvido (OD), demanda bioquímica de oxigênio (DBO) e mensuração da temperatura. Além disso, foram realizadas medições hidrológicas em todos os PM. Com base nos resultados das análises laboratoriais realizou-se a calibração do modelo QUAL-UFMG para a avaliação da capacidade de autodepuração. A modelagem da qualidade da água, na campanha de inverno, foi a que apresentou maior grau de deterioração da qualidade da água, com baixos níveis de OD e elevada concentração de DBO, indicando que no período de estiagem reduz-se a capacidade de diluição frente aos despejos de efluentes. Conclui-se que o Rio Ligeiro se encontra deteriorado desde a nascente e que a sua capacidade de autodepuração apresenta condições críticas no período de menor vazão.

Palavra-chave: Qualidade da água, Autodepuração, Rio Ligeiro, QUAL-UFMG.

\begin{abstract}
The objective of this study was to monitor the water quality and evaluate the self-purification capacity of the Ligeiro River, from one of the sources to the confluence with the Chopim River. Six monitoring points (PM01 to PM06) were established along the route. Water samples were collected in the different seasons of the year 2017 for analysis of dissolved oxygen (DO), biochemical oxygen demand (BOD) and temperature determination. In addition, hydrological measurements were performed on all PMs. Based on the results of the laboratory analysis, the calibration of the QUAL-UFMG model was carried out for the evaluation of the self-purification capacity. The water quality modeling, in the winter season, presented the highest degree of water quality deterioration, with low OD levels and high BOD concentration, indicating that in the dry season the dilution capacity is reduced to effluent discharges. It is concluded that the Ligeiro River has deteriorated from the source and that its capacity of self-purification presents critical conditions in the period of lower flow.
\end{abstract}

Keywords:Water quality, self-purification, Ligeiro River, QUAL-UFMG

\section{INTRODUÇÃO}

A disponibilidade da água, quantidade e qualidade, é essencial para a sobrevivência, sendo considerada como um fator limitante para o desenvolvimento de uma região. Diante desse aspecto, a água tem se tornado como um dos principais recursos do planeta. Embora a água seja considerada renovável a sua disponibilidade pode se tornar escassa em função da degradação pelas atividades antropogênicas.
A alteração da disponibilidade de água tem como fator principal o crescimento populacional, pois isso demanda ocupação do solo, aumento do consumo de água para as diversas atividades agrícolas e urbanas que, consequentemente, implica na geração de efluentes que, por sua vez, chegam aos rios por meio do escoamento superficial ou de lançamentos pontuais, tendo como resultado a degradação dos recursos hídricos. 
Nesse contexto, a água encontrada na natureza não é pura, e sim uma dissolução aquosa que contém em diferentes proporções sais, gases e matéria orgânica (Benetti \& Bidone, 2009). Portanto, as condições naturais, como clima, geologia, precipitação, intemperismo, tipo de solo, $\mathrm{e}$ as atividades antropogênicas, tais como lançamentos de efluentes domésticos e industriais, aplicação de agroquímicos, práticas agrícolas, disposição de resíduos sólidos entre outros, determinam a qualidade da água de uma determinada bacia hidrográfica (Sperling, 2014). Logo, infere-se que a poluição das águas é resultante principalmente das atividades antropogênicas, tendo em vista que os lançamentos de efluentes domésticos e industriais tendem a ser constantes, enquanto que a poluição por processos naturais, escoamento superficial, apresenta sazonalidade em função das condições climáticas (Sundaray et al., 2006).

A introdução de matéria orgânica nos corpos hídricos tem como consequência a redução da concentração do oxigênio dissolvido (OD) no meio, pois, os microrganismos utilizam o OD para a decomposição das substâncias orgânica (Vargas \& Marques, 2015). A recuperação do OD, nas condições naturais, irá depender das características do corpo hídrico e dos efluentes lançados, sendo que o reestabelecimento das condições de equilíbrio denomina-se autodepuração.

A avaliação da qualidade da água é de difícil integração, pois envolve diversos aspectos e processos. Diante disso, modelos matemáticos, abordagens de otimização e sistemas de gerenciamento foram e vem sendo desenvolvidos com o objetivo de identificar e diagnosticar as alterações da qualidade das águas (Carvalho et al., 2016), assim como prever cenários de forma a manter as condições mínimas de qualidade para determinado uso. $\mathrm{O}$ modelo matemático pioneiro de qualidade da água foi proposto por Streeter e Phelps, em 1925, no Rio Ohio, EUA. A partir desse modelo, diversos outros foram desenvol-vidos, incluindo variáveis e coeficientes descon-siderados anteriormente, no entanto mantendo sempre a estrutura conceitual (Salla et al., 2013), entre eles o QUAL2E, CE-QUAL-W2, Mike11, Wasp e QUAL-UFMG (Fleck et al., 2013).

O modelo QUAL-UFMG é um programa na plataforma Excel criado por Sperling (2014), com base no modelo matemático QUAL2-E. O modelo QUAL2-E foi desenvolvido pela Environmental Protection Agency (EPA), sendo este o modelo mais conceituado, atualmente, na modelagem de qualidade da água de rios (Batista \& Cabral, 2017).

No modelo QUAL-UFMG foram aplicadas simplificações em relação ao QUAL2-E. As simplificações referem-se a: não inclusão de algas e as suas inter-relações com os demais constituintes; não consideração de dispersão longitudinal; integração pelo método de Euler. Neste modelo, pode ser realizada a modelagem para: demanda bioquímica de oxigênio $\left(\mathrm{DBO}_{5}\right)$; OD; nitrogênio total e suas frações; fósforo total e suas frações; coliformes termotolerantes; Escherichia coli (Teodoro et al., 2013).

Rodrigues et al. (2009) simularam a capacidade de autodepuração do Rio Anhanduí, Mato Grosso do Sul, considerando o lançamento da ETE com $0 \%, 70 \%$ e $92 \%$ de eficiência de remoção de $\mathrm{DBO}_{5}$. Na simulação de eficiência de $0 \%$ apenas $32,7 \%$ da extensão do trecho atendeu ao padrão de qualidade para $\mathrm{OD}$, enquadrando o rio como classe 2. Para as demais eficiências em todo o trajeto atende ao parâmetro OD para a classe supracitada. $\mathrm{Na}$ análise da DBO os padrões de qualidade não foram atendidos em nenhuma das simulações. Portanto, o corpo hídrico não tem capacidade de autodepuração.

Costa \& Teixeira (2010), na avaliação da capacidade de autodepuração do Ribeirão Ouro delimitaram fisicamente as zonas de autodepuração a partir do perfil de concentração de oxigênio dissolvido, tendo como resultado que em 5,1 km de extensão refere-se à zona de águas limpas, 1,5 km zona de degradação, $3,7 \mathrm{~km}$ zona de decomposição ativa e $6,7 \mathrm{~km}$ na zona de recuperação.

Moruzzi et al. (2012) realizaram a avaliação do Córrego água Branca, Itarapina, São Paulo, e verificaram que o corpo hídrico não atende aos padrões de qualidade de OD para rios de classe 2 em toda a sua extensão. Tais resultados ocorrem devido aos lançamentos pontuais e difusos, oriundas de esgoto das áreas urbanas e agrícolas. Segundo os autores para manter a concentração de OD acima do limite estabelecido deve ser implanado sistema de tratamento de efluentes com no mínimo $75 \%$ de eficiência de remoção de $\mathrm{DBO}_{5}$.

Teodoro et al. (2013), realizaram a simulação de lançamento de efluentes de seis atividades ao longo do Rio Taquarizinho, utilizando o modelo QUAL-UFMG. A modelagem foi realizada para três vazões diferentes. Os resultados da simulação para o parâmetro OD e DBO5 mostrou que a 
porcentagem de atendimento aos padrões de qualidade estabelecido na legislação foi em torno de $90 \%$ do trecho do rio, para as diferentes vazões. Concluíram que a bacia hidrográfica do Rio Taquarizinho, mesmo com elevadas atividades antrópicas, apresenta capacidade de autodepuração para a instalação de novos empreendimentos com lançamentos de efluentes.

Oliveira Filho \& Lima Neto (2017), aplicaram o modelo QUAL-UFMG no Rio Poti, Terezina, Piauí, para a modelagem de OD, DBO e coliformes termotolerantes considerando múltiplas fontes de lançamentos de efluentes nas condições de vazão críticas. A calibração do modelo foi satisfatória para todos os parâmetros, sendo que a diferença entre os dados modelados e os observados foram inferiores a $20 \%$. Na simulação de vazão máxima os coliformes termotolerantes apresentaram desconformidade com a Resolução CONAMA no 357/2005, para corpos hídricos de classe 2 , em $58 \%$ de extensão do rio, enquanto que o OD e a DBO atenderam em toda a extensão. Para a vazão mínima verificou-se a desconformidade para os três parâmetros, indicando que as condições de qualidade são influenciadas pela diluição.

Salla et al. (2013), estudaram a capacidade de autodepuração do Rio Jordão, tendo como fonte pontual a contribuição real do córrego Brejo Alegre e também simularam cenários 1 e 2 , de lançamento de efluentes domésticos na confluência destes corpos hídricos. O estudo foi realizado no período de estiagem. Na modelagem das condições reais foi verificado, que os parâmetros OD, nitrogênio e suas frações, fósforo total e coliformes termotolerantes atendem aos limites preconizados na Resolução do CONAMA n ${ }^{\circ} 357 / 2005$, para corpos hídricos classe 2 .

Enquanto que a DBO apresentou concentrações acima do limite em todo o trecho modelado. No cenário 1 foi proposto o sistema de tratamento secundário composto de lagoa anaeróbia seguida de lagoa facultativa e no cenário 2 o sistema de tratamento secundário de lodo ativado convencional, com eficiência de $75 \%$ e $85 \%$, respectivamente. Em ambos os cenários o Rio Jordão não apresentou capacidade de autodepuração devido ao não atendimento nos teores de OD e DBO.

A bacia hidrográfica do Rio Ligeiro diante das pressões antrópicas exercidas já foi objeto de diversos estudos, tais como: avaliação da influência da vegetação na estabilidade de taludes (Tabalipa \& Fiori, 2008a); influência dos ventos na estabilidade de taludes (Tabalipa \&Fiori, 2008b); alterações hidrológicas decorrentes da mudança de uso e ocupação do solo (Jabur, 2010); estimativa de vazão máxima e capacidade de saturação hídrica (Jabur \& Rizzi, 2011); caracterização dos solos na estabilidade de taludes (Tabalipa \& Fiori, 2012); e avaliação da qualidade da água (Watthier et al., 2008; Pizatto, 2011; Heinz et al.,2016).

Nos estudos referentes à qualidade da água do Rio Ligeiro realizados até a presente data não foi abordado o monitoramento com a utilização de instrumentos e/ou ferramentas que possibilitassem a avaliação da capacidade de autodepuração. Portanto, este estudo tem como objetivo a aplicação da modelagem da qualidade da água para o parâmetro OD e DBO utilizando o modelo QUAL-UFMG para a avaliação da capacidade de autodepuração do Rio Ligeiro até a sua foz com o Rio Chopim.

\section{CARACTERIZAÇÃO DA ÁREA DE ESTUDO}

A bacia hidrográfica do Rio Ligeiro situa-se entre os paralelos $26^{\circ} 01^{\prime} 24^{\prime \prime}$ e $26^{\circ} 16^{\prime} 51^{\prime \prime}$ de

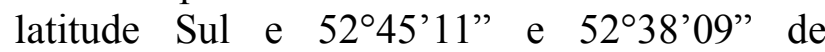
longitude Oeste, nos municípios de Bom Sucesso do Sul e Pato Branco, mesorregião Sudoeste Paranaense. A localização geográfica da bacia hidrográfica do Rio Ligeiro juntamente com os cursos de água e área urbana do município de Pato Branco encontra-se ilustrada na figura 1 Figura 1.

O Rio Ligeiro possui extensão de 59,06 km com área de drenagem de 17.333,35 ha, sendo que 695,87 ha (4\%) se localizam no município de Bom Sucesso do Sul e o restante pertence ao município de Pato Branco. Suas nascentes localizam-se na Zona Sul do município de Pato Branco, na altitude em torno de $860 \mathrm{~m}$, e sua foz na margem esquerda do Rio Chopim, altitude em torno de $500 \mathrm{~m}$, na divisa com o município de Coronel Vivida.

O Rio Ligeiro tem como principais afluentes o Arroio Ligeiro, na margem direita, Córrego Penso, Rio Passo da Pedra e Arroio Gramado, ambos na margem esquerda (Tomazoni, 2009). Além desses corpos hídricos, o Rio Ligeiro possui diversos outros corpos hídricos compondo, assim, a sua rede de drenagem. Salienta-se que à maioria dos cursos de água localizados na área urbana do município de Pato Branco encontram-se canalizados na parte 
superior e lateral.

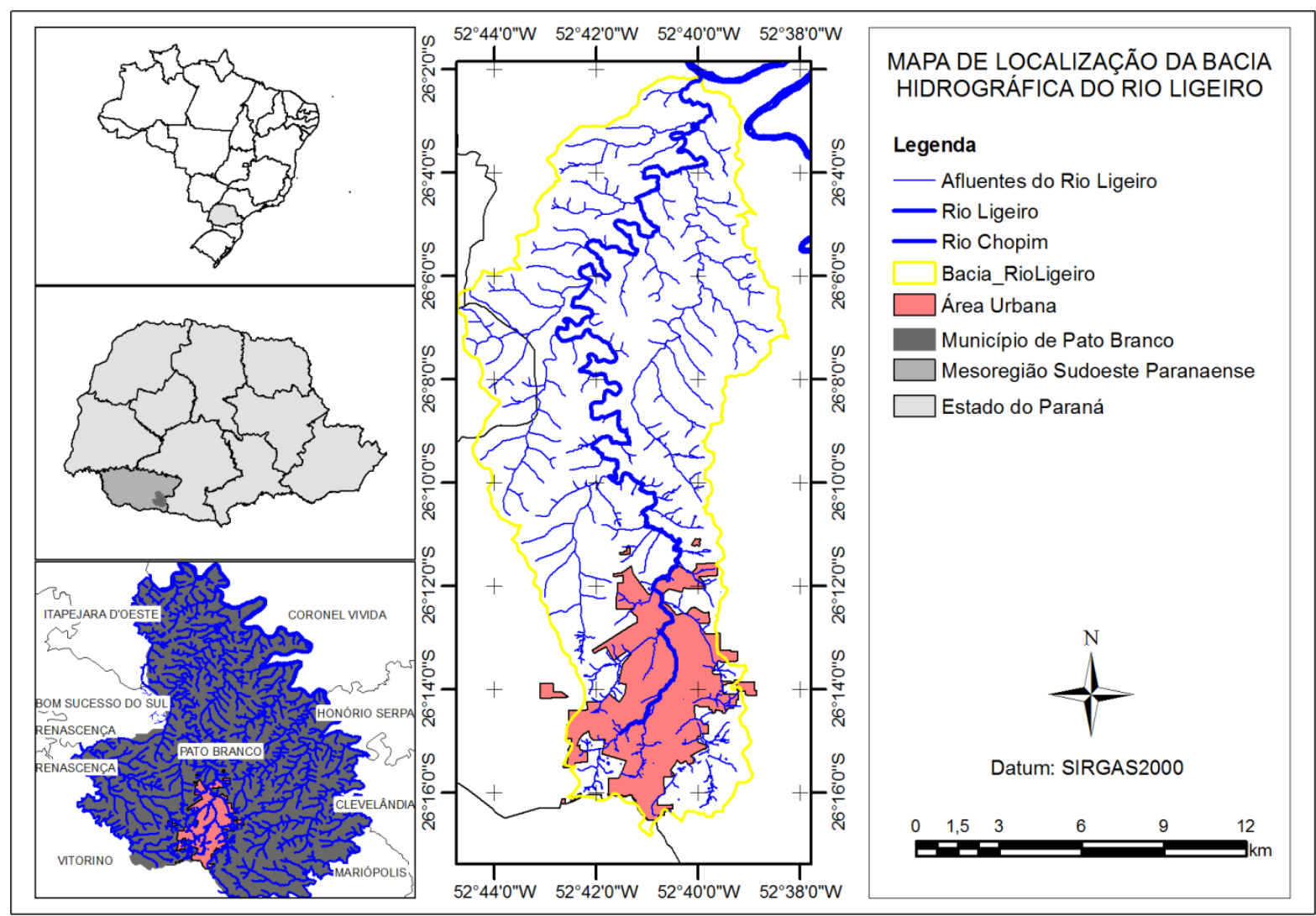

Figura 1 - Mapa de localização geográfica da bacia hidrográfica do Rio Ligeiro.

O município de Pato Branco possui área territorial de 53.847,76 ha, com população de 72.370 habitantes, censo demográfico de 2010, destes 68.091 habitantes (94\%) domiciliados na área urbana, para o ano de 2017 estima-se a população de 80.710 habitantes (IBGE, 2017). A área urbana do município de Pato Branco ocupa área de 2.559,37 ha, destes aproximadamente 96\% encontra-se na bacia hidrográfica do Rio Ligeiro (figura 1), o que representa em torno de $15 \%$ da área total da bacia hidrográfica do Rio Ligeiro.

Os efluentes domésticos do município de Pato Branco são coletados e enviados para a ETE da SANEPAR, sendo que o atendimento de esgoto é de $91,4 \%$ com 18.346 ligações atendendo a 24.270 unidades (IBGE, 2017). O uso principal das águas do Rio Ligeiro refere-se ao transporte e diluição de efluentes de origem doméstica e industrial, não havendo captação de água com outorgas vigentes junto ao órgão competente (Paraná, 2017).

De acordo com a classificação de Koppen o clima é do tipo Cfb (Tabalipa \& Fiori, 2008b; Tomazoni \& Guimarães, 2015), caracterizado pelo clima temperado e úmido, com temperatura média no mês mais quente inferior a $22{ }^{\circ} \mathrm{C}$.

A precipitação média anual para o município de Pato Branco é de $2.098 \mathrm{~mm}^{\mathrm{ano}}{ }^{-1}$, sendo o mês de agosto mais seco, com precipitação total mensal média de 113,6 mm, e o mais chuvoso o mês de outubro, com precipitação total mensal média de 242,5 mm, registros referentes ao período de 1979 a 2016 (IAPAR, 2017).

\section{METODOLOGIA}

\section{Localização dos pontos de monitoramento e} trechos

Para a seleção dos pontos de monitoramento (PM) utilizou-se o banco de dados geográficos do município de Pato Branco, cedidos pelo Prof. Dr. Julio Caetano Tomazoni, contendo os cursos de água e imagens do satélite QuickBird de agosto de 2005 (Tomazoni, 2009). Os critérios considerados para seleção dos PM foram: extensão do rio; diversidade de uso e ocupação do solo; localização dos tributários; localização dos pontos de lançamentos de efluentes; características hidráulicas-hidrológicas; facilidade de acesso; disponibilidade de recursos humanos e financeiros. Posteriormente, realizou-se a visitação in loco para verificação das condições de acessibilidade, coleta das amostras e de obtenção dos dados de campo. 
Com base nas visitas aos PM, considerando a disponibilidade de recursos humanos e financeiros e a extensão do Rio Ligeiro, estabeleceram-se seis PM, sendo adotadas as seguintes nomenclaturas: Ponto 01 (PM01), Ponto 02 (PM02), Ponto 03 (PM03), Ponto 04 (PM04), Ponto 05 (PM05) e Ponto 06 (PM06). O monitoramento abrangeu desde uma das nascentes (afluente) do Rio Ligeiro até a confluência com o Rio Chopim. Portanto, o monitoramento da qualidade da água compreendeu uma extensão de $59,19 \mathrm{~km}$, sendo $5,95 \mathrm{~km}$ de extensão de um afluente e 53,24 km o Rio Ligeiro. A localização geográfica dos PM foi obtida com o uso de um GPS (Global Position System) de navegação EtrexGarmin da

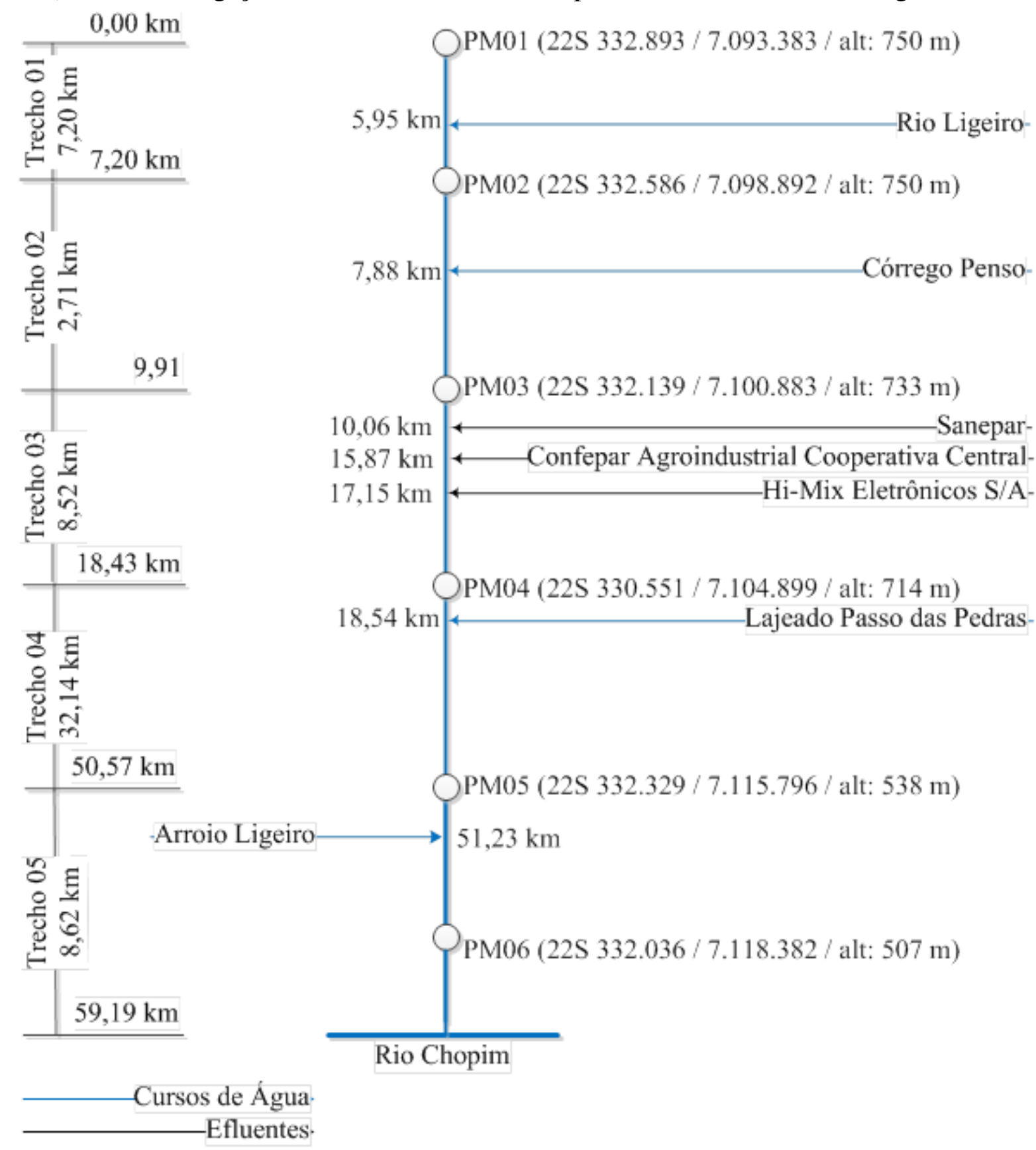

Universidade Tecnológica Federal do Paraná (UTFPR). Em todos os PM foram realizadas a medições de largura, profundidade, velocidade e vazão e coleta das amostras de água.

A partir da definição dos PM demarcaram-se os trechos de modelagem, sendo, assim, definidos cinco trechos: Trecho 01; Trecho 02; Trecho 03; Trecho 04; Trecho 05. Na figura 2 é apresentado o diagrama unifilar do Rio Ligeiro contendo os PM, afluentes principais, lançamentos pontuais de efluentes com outorgas de uso, coordenadas em UTM (Universal Transversa de Mercator) e a localização em termos de extensão em relação ao PM01. Na figura 3 Figura 3é apresentada a localização espacial dos PM na bacia hidrográfica. 


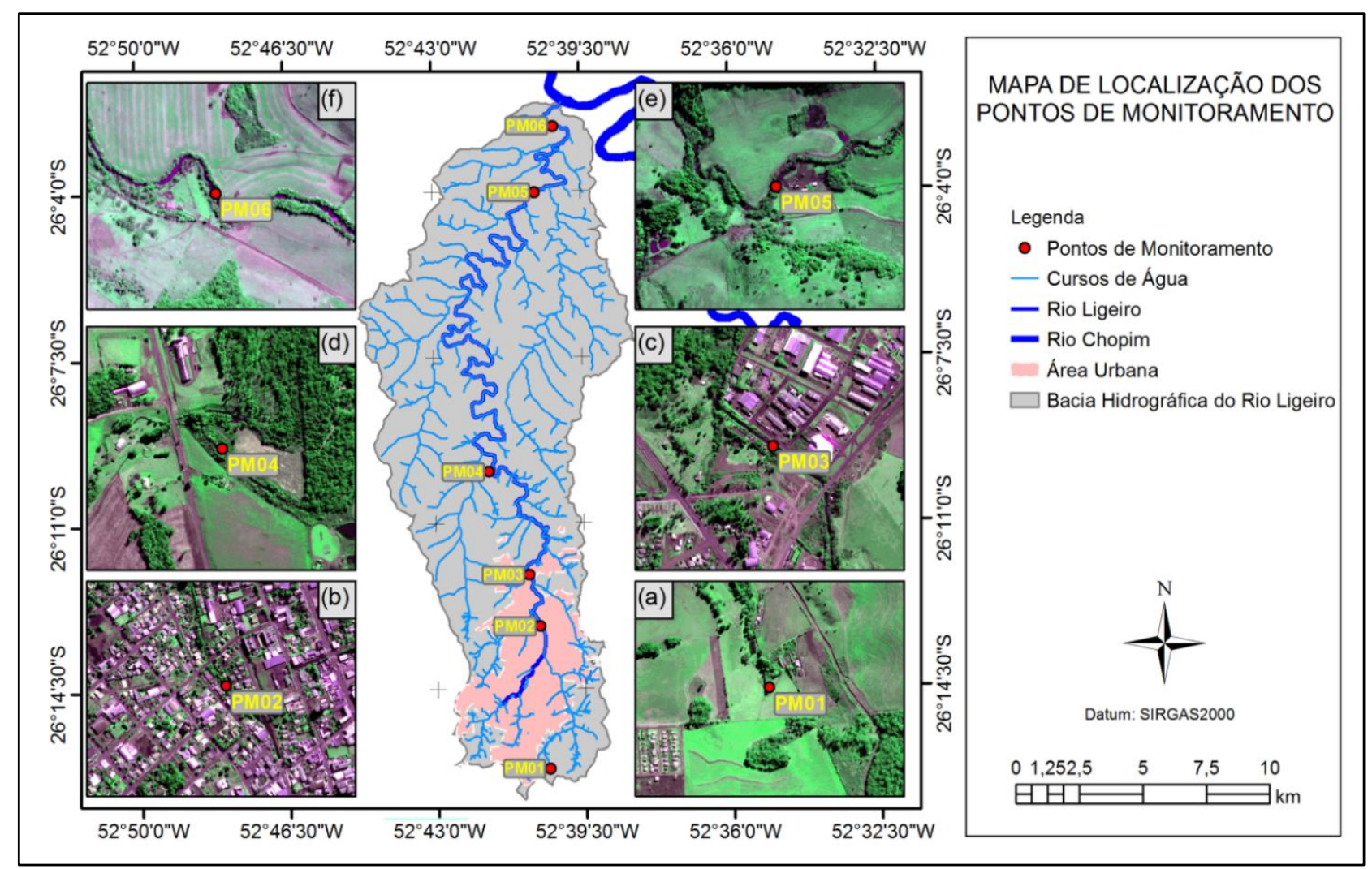

Figura 3 - Localização geográfica dos Pontos de Monitoramento na bacia hidrográfica do Rio Ligeiro.

\section{DADOS DE CAMPO}

Para a calibração e modelagem da capacidade de autodepuração são necessários diversos parâmetros e variáveis de entrada, tais como hidrológicos e de qualidade da água. A ABNT (1987), orienta que o monitoramento de qualidade da água deve compreender períodos de variações das condições críticas de vazão do curso de água e variação estacional. Neste sentido, considerando as variações em função das estações do ano e o histórico de precipitações foi realizado o monitoramento nos seguintes períodos: fevereiro de 2017 - campanha de verão; junho de 2017 campanha de outono; agosto de 2017 - campanha de inverno; outubro de 2017 - campanha de primavera. Os meses de fevereiro e junho correspondem aos meses com precipitação próximos da média, enquanto que o mês de junho e outubro se refere aos meses de estiagem e chuvoso, respectivamente. Os parâmetros e variáveis mensurados em cada PM foram: largura, profundidade, velocidade, vazão, coleta de amostras de água para determinação de OD, DBO e temperatura.

Para a determinação do OD, DBO e temperatura as amostras de água foram coletadas manualmente na posição central da seção do curso de água, mergulhando os frascos no sentido contrário ao fluxo. As análises foram realizadas pelo Laboratório de Qualidade Agroindustrial (LAQUA), da UTFPR Campus Pato Branco, com base na metodologia descrita no Standard Methods for the Examination of Water and Wastewater, (APHA, 2005). As amostras submetidas à análise de OD foram preservadas com solução de iodeto alcalino com azida de sódio e sulfato de manganês. A temperatura foi determinada em campo utilizando termômetro de mercúrio.

Os dados hidrológicos (largura, profundidade, velocidade e vazão) foram mensurados utilizando o método convencional com molinete hidrométrico, exceto para o PM01.

A área da seção molhada foi obtida através da medição da largura do curso de água e da profundidade em um número significativo de pontos ao longo da seção, denominada como verticais. Nas verticais fixou-se a haste do molinete e este, por sua vez, foi posicionado em diferentes profundidades para a mensuração da velocidade. Para o posicionamento do molinete adotou o método dos dois pontos (Santos et al.2001). No PM01 o monitoramento da vazão foi através do método volumétrico, mensurando o tempo necessário para encher um bécker com capacidade de $500 \mathrm{~mL}$, tais medições foram realizadas em triplicata. 


\section{MODELAGEM DA QUALIDADE DA ÁGUA}

A aplicação de modelos de qualidade da água tem como objetivo a avaliação da capacidade do rio frente aos impactos oriundos de lançamentos de efluentes, permitindo assim a análise de cenários de intervenção e implantação de medidas de controle (Salla et al., 2013).

A modelagem da qualidade da água pode ser realizada por diversos modelos. Neste estudo optou-se pelo modelo QUAL-UFMG, desenvolvido na plataforma Microsoft Excel por Sperling (2014), sendo que foi modelada a DBO e o OD, pois, tais parâmetros representam os principais fenômenos de poluição dos corpos hídricos.

Cabe destacar que para a aplicação dessa modelagem desconsiderou a contribuição difusa de DBO, consumo de oxigênio pela nitrificação, fotossíntese e respiração algal.

Para a aplicação desse modelo são necessários dados de entrada, tais como: trechos de monitoramento; parâmetros de qualidade da água; dados hidráulico-hidrológicos do curso de água; dados de captação de água e de lançamentos de efluentes; coeficiente de desoxigenação (K1); coeficiente de decomposição $(\mathrm{Kd})$; coeficiente de sedimentação $(\mathrm{Ks})$; coeficiente de reaeração $(\mathrm{K} 2)$.

Os dados de outorgas de direito e dos cadastros de usos insignificantes foram obtidos através de consulta junto ao site do Instituto de Águas do Paraná, sendo possível identificar a localização geográfica, vazões de captação, vazão de lançamentos e concentrações máximas de $\mathrm{DBO}_{5}$.

Ao longo do percurso os corpos hídricos recebem entrada de tributários e/ou até mesmo o lançamento pontual de efluentes e/ou captações de água, logo se tem uma variação da vazão ao longo do percurso do rio. Em relação ao Rio Ligeiro, conforme apresentado na Figura 2, ocorre à entrada de tributários e o lançamento de efluentes da ETE da SANEPAR e de atividades industriais, não sendo identificados pontos de captação de água. Com base neste contexto, foi realizado o balanço de vazão considerando a diferença de vazão entre os PM e os lançamentos de efluentes.

Os coeficientes de desoxigenação $\left(\mathrm{K}_{1}\right)$, coeficiente de decomposição $\left(K_{d}\right)$ e coeficiente de sedimentação $\left(K_{s}\right)$ são denominados como coeficiente de remoção de $\mathrm{DBO}_{5}$. Na Tabela 1 são apresentados os valores dos coeficientes corriqueiramente utilizados na modelagem de qualidade da água, sendo que tais valores foram utilizados de acordo com as características de cada trecho.

Tabela 1 - Valores típicos dos coeficientes de remoção de DBO.

\begin{tabular}{|c|c|c|c|c|c|}
\hline \multicolumn{6}{|c|}{ Valores típicos dos coeficientes de remoção de DBO, base e, $20^{\circ} \mathrm{C}$} \\
\hline \multirow[t]{2}{*}{ Origem } & \multirow{2}{*}{$\begin{array}{l}K_{1} \\
\text { (laboratório) }\end{array}$} & \multicolumn{2}{|c|}{$\begin{array}{l}\text { Rios Rasos } \\
\text { (prof. }<1,0 \mathrm{~m} \text { ou } 1,5 \mathrm{~m})\end{array}$} & \multicolumn{2}{|c|}{$\begin{array}{l}\text { Rios profundos } \\
\text { (prof.>1,0 m ou 1,5 m) }\end{array}$} \\
\hline & & $\mathbf{K}_{\mathbf{d}}$ & $\mathbf{K}_{\mathrm{s}}$ & $\mathbf{K}_{\mathbf{d}}$ & $\mathbf{K}_{\mathrm{s}}$ \\
\hline $\begin{array}{l}\text { Curso de água recebendo esgoto } \\
\text { bruto concentrado }\end{array}$ & $0,35-0,45$ & $0,50-1,00$ & $0,10-0,35$ & $0,35-0,50$ & $0,05-0,20$ \\
\hline $\begin{array}{l}\text { Curso de água recebendo esgoto } \\
\text { bruto de baixa concentração }\end{array}$ & $0,30-0,40$ & $0,40-0,80$ & $0,05-0,25$ & $0,30-0,45$ & $0,00-0,15$ \\
\hline $\begin{array}{l}\text { Curso de água recebendo efluente } \\
\text { primário }\end{array}$ & $0,30-0,40$ & $0,50-0,80$ & $0,05-0,10$ & $0,30-0,45$ & $0,00-0,05$ \\
\hline $\begin{array}{l}\text { Curso de água recebendo efluente } \\
\text { secundário }\end{array}$ & $0,12-0,24$ & $0,12-0,24$ & - & $0,12-0,24$ & - \\
\hline Curso de água com águas limpas & $0,08-0,20$ & $0,08-0,20$ & - & $0,08-0,20$ & - \\
\hline
\end{tabular}

Nota: prof. - profundidade

Sperling (2014), descreve que o coeficiente de reaeração $\left(\mathrm{K}_{2}\right)$ pode ser obtido, basicamente, por três métodos: valores médios tabelados; valores calculados com base nas características hidráulicas do curso de água; correlação com a vazão do curso de água. Os valores de $\mathrm{K}_{2}$, para cada trecho, foram obtidos com base nas características hidráulicas do curso de água, de acordo com a faixa de aplicabilidade (Sperling,
2014). Após a obtenção dos valores de $\mathrm{K}_{2}$, os mesmos foram corrigidos para as respectivas temperaturas registradas nos dias de coleta.

\section{Calibração dos coeficientes de remoção de DBO5}

Para que os modelos representem as condições mais próximas da realidade realiza-se a calibração do modelo. Neste estudo, o modelo QUAL-UFMG foi calibrado para as variáveis de 
$\mathrm{DBO}_{5}$ e OD.A calibração foi realizada de forma automática, variando os valores dos coeficientes de remoção de $\mathrm{DBO}_{5}$, utilizando a ferramenta solver da plataforma Excel.

Para a calibração utilizou-se o coeficiente de eficiência de Nash-Sutcliffe (NSE), Equação 1.

$$
N S E=1-\left\{\left[\sum_{i=1}^{n}\left(Y_{o b s}-Y_{\text {model }}\right)^{2}\right]\left[\sum_{i=1}^{n}\left(Y_{o b s, i}-Y_{\text {med }, o b s}\right)^{2}\right]\right\}^{-1} \text { Eq. } 1
$$

Onde: NSE é o coeficiente de eficiência de Nash-Sutclifffe, adimensional; $Y_{o b s}$ é o valor observado; $Y_{\text {model }}$ é o valor modelado; $Y_{\text {med, obs é a }}$ média dos valores observados. $\mathrm{O}$ coeficiente de $N S E$ varia de $-\infty$ a 1 , sendo que quanto mais próximo de 1 , melhor será o ajuste entre os dados observados e modelados (Salla et al., 2013).
Portanto, na ferramenta "solver" do Excel foi buscada a maximização deste coeficiente.

Não foram calibrados os valores do coeficiente de reaeração $\left(\mathrm{K}_{2}\right)$, pois os mesmos foram calculados de acordo com as características hidrológicas de cada trecho.

\section{RESULTADOS E DISCUSSÕES}

A modelagem da avaliação da capacidade de autodepuração foi realizada para a campanha de verão, campanha de outono e campanha de inverno.

Para a campanha de primavera não foi possível à aplicação da modelagem da qualidade da água devido à dificuldade da obtenção dos dados hidrológicos, elevada velocidade e vazão, nos dias da coleta das amostras.

\section{Dados de Campo}

Os dados hidrológicos obtidos nos PM das respectivas campanhas de monitoramento encontram-se apresentados na tabela 2.

Analisando os valores de vazão (Q), tabela 2, observa-se que a campanha de inverno corresponde a de menor vazão, enquanto que a campanha de outono foi a de maior vazão registrada.

Na tabela 3 são apresentados os resultados das análises laboratoriais dos parâmetros de qualidade da água para as diferentes campanhas de monitoramento.

Tabela 2 - Dados hidrológicos dos PM nas diferentes campanhas de monitoramento.

\begin{tabular}{|c|c|c|c|c|c|c|c|c|c|c|c|c|}
\hline \multirow[b]{2}{*}{ PM } & \multicolumn{4}{|c|}{ Campanha de verão } & \multicolumn{4}{|c|}{ Campanha de outono } & \multicolumn{4}{|c|}{ Campanha de inverno } \\
\hline & $\begin{array}{c}\mathbf{L} \\
(\mathbf{m})\end{array}$ & $\underset{(\mathbf{m})}{\mathbf{p}}$ & $\begin{array}{c}\mathbf{v} \\
\left(\mathbf{m s}^{-1}\right)\end{array}$ & $\begin{array}{c}\mathbf{Q} \\
\left(\mathbf{m s}^{-3}\right)\end{array}$ & $\begin{array}{c}\mathbf{L} \\
(\mathbf{m})\end{array}$ & $\underset{(\mathbf{m})}{\mathbf{p}}$ & $\begin{array}{c}\mathbf{v} \\
\left(\mathbf{m s}^{-1}\right)\end{array}$ & $\begin{array}{c}\mathbf{Q} \\
\left(\mathbf{m s}^{-3}\right)\end{array}$ & $\begin{array}{c}\mathbf{L} \\
(\mathbf{m})\end{array}$ & $\underset{(\mathbf{m})}{\mathbf{p}}$ & $\begin{array}{c}\mathbf{v} \\
\left(\mathbf{m s}^{-1}\right)\end{array}$ & $\begin{array}{c}\mathbf{Q} \\
\left(\mathrm{ms}^{-3}\right)\end{array}$ \\
\hline PM01 & 0,10 & 0,10 & 0,01 & 0,0001 & 0,20 & 0,15 & 0,02 & 0,001 & 0,10 & 0,10 & 0,008 & 0,0001 \\
\hline PM02 & 6,00 & 0,27 & 0,41 & 0,66 & 6,44 & 0,38 & 0,61 & 1,50 & 4,70 & 0,21 & 0,68 & 0,65 \\
\hline PM03 & 9,50 & 0,32 & 0,27 & 0,83 & 10,00 & 0,49 & 0,36 & 1,76 & 8,00 & 0,27 & 0,31 & 0,67 \\
\hline PM04 & 9,20 & 0,35 & 0,56 & 1,79 & 9,40 & 0,51 & 0,53 & 2,56 & 8,50 & 0,28 & 0,37 & 0,87 \\
\hline PM05 & 13,70 & 0,54 & 0,47 & 3,47 & 13,55 & 0,54 & 0,86 & 6,27 & 11,00 & 0,29 & 0,73 & 2,36 \\
\hline PM06 & 15,50 & 0,39 & 0,74 & 4,46 & 15,50 & 0,60 & 0,96 & 8,89 & 10,50 & 0,31 & 0,83 & 2,71 \\
\hline
\end{tabular}

Nota: L=Largura, $\mathrm{p}=$ profundidade média, v=velocidade média, $\mathrm{Q}=$ vazão.

Tabela 3 - Dados do monitoramento da qualidade da água nas diferentes campanhas de monitoramento.

\begin{tabular}{|c|c|c|c|c|c|c|c|c|c|}
\hline \multirow[b]{2}{*}{$\mathbf{P M}$} & \multicolumn{3}{|c|}{ Campanha de verão } & \multicolumn{3}{|c|}{ Campanha de outono } & \multicolumn{3}{|c|}{ Campanha de inverno } \\
\hline & $\begin{array}{c}\text { DBO } \\
\left(\mathrm{mgL}^{-1}\right)\end{array}$ & $\underset{\left(\mathrm{mgL}^{-1}\right)}{\mathrm{OD}}$ & $\begin{array}{c}\mathrm{T} \\
\left({ }^{\mathbf{0}} \mathrm{C}\right)\end{array}$ & $\begin{array}{c}\text { DBO } \\
\left(\mathrm{mgL}^{-1}\right)\end{array}$ & $\begin{array}{c}\text { OD } \\
\left(\mathrm{mgL}^{-1}\right)\end{array}$ & $\begin{array}{c}\mathbf{T} \\
\left({ }^{\circ} \mathrm{C}\right)\end{array}$ & $\begin{array}{c}\text { DBO } \\
\left(\mathrm{mgL}^{-1}\right)\end{array}$ & $\begin{array}{c}\text { OD } \\
\left(\mathrm{mgL}^{-1}\right)\end{array}$ & $\begin{array}{c}\mathbf{T} \\
\left({ }^{\mathbf{o}} \mathbf{C}\right)\end{array}$ \\
\hline PM01 & 8,40 & 7,00 & 21,0 & 19,20 & 7,00 & 20,0 & 10,80 & 7,50 & 16,5 \\
\hline$\overline{\text { PM02 }}$ & 6,00 & 7,10 & 24,0 & 21,00 & 7,60 & 18,0 & 40,20 & 6,10 & 16,5 \\
\hline PM03 & 4,80 & 7,10 & 25,0 & 21,60 & 7,30 & 16,0 & 21,40 & 7,00 & 13,0 \\
\hline PM04 & 3,60 & 5,80 & 25,0 & 9,60 & 7,10 & 15,0 & 11,00 & 3,40 & 14,0 \\
\hline$\overline{\text { PM05 }}$ & 6,40 & 8,20 & 26,0 & 14,40 & 9,10 & 17,0 & 30,40 & 7,00 & 18,0 \\
\hline PM06 & 7,80 & 9,00 & 19,0 & 13,20 & 8,80 & 17,0 & 38,40 & 7,30 & 17,0 \\
\hline
\end{tabular}

De maneira geral as concentrações mais elevadas de $\mathrm{DBO}_{5}$ foram registradas nas campanhas de baixa e alta vazão do curso de água, campanha de inverno e outono, respectivamente. Já em relação ao OD, em termos gerais, os mínimos teores foram encontrados na campanha de menor vazão, campanha de inverno. Cabe destacar que a concentração de OD foram acima dos padrões de qualidade estabelecidos na Resolução do CONAMA no 357/2005 em quase todos os PM, $5,00 \mathrm{mgL}^{-1}$.

\section{Determinação dos Coeficientes do Modelo}

$\mathrm{O}$ coeficiente de reaeração $\left(\mathrm{K}_{2}\right)$ foi calculado de acordo com os valores de velocidade e 
profundidade considerando o intervalo de utilização da respectiva equação.

As profundidades encontradas foram entre 0,10 $\mathrm{m}$ a $0,60 \mathrm{~m}$, e velocidades entre $0,01 \mathrm{~ms}^{-1}$ a 0,96 $\mathrm{ms}^{-1}$, tabela 2 , portanto, tais valores encontram-se na faixa de aplicação da equação proposta por de Owens et al. (1964), segundo Sperling (2014).

$\mathrm{Na}$ tabela 4 são apresentados os valores calculados para o coeficiente de reaeração $\left(\mathrm{K}_{2}\right)$ corrigidos para as respectivas temperaturas registradas nas campanhas de monitoramento. Ressalta-se que os valores foram mantidos constantes para cada trecho.

Tabela 4 - Coeficiente de reaeração $\left(\mathrm{K}_{2}\right)$ calibrados para cada trecho de modelagem.

\begin{tabular}{l|l|l|l}
\hline \multirow{2}{*}{$\begin{array}{l}\text { Identificação } \\
\text { do Trecho }\end{array}$} & \multicolumn{4}{|l}{ Coeficiente de reaeração $\mathbf{K}_{\mathbf{2}}\left(\mathbf{d i a}^{-1}\right)$} \\
\cline { 2 - 4 } ) & Verão & Outono & Inverno \\
\hline Trecho 01 & 33,66 & 22,80 & 67,59 \\
\hline Trecho 02 & 19,95 & 9,54 & 25,09 \\
\hline Trecho 03 & 28,22 & 10,95 & 24,30 \\
\hline Trecho 04 & 11,25 & 13,30 & 36,77 \\
\hline Trecho 05 & 28,51 & 12,36 & 38,94 \\
\hline
\end{tabular}

Os valores do coeficiente de reaeração no Trecho 01 foram significativamente superiores aos demais trechos na mesma campanha de modelagem, tais resultados podem ser explicados pelos baixos valores de profundidade média deste trecho. Neste trecho o leito é pedregoso o que faz com que crie turbulência das águas e consequentemente maior capacidade de reposição de oxigênio na massa líquida.

Os coeficientes de reaeração $\left(\mathrm{K}_{2}\right)$ calculados para a campanha de inverno foram superiores as outras campanhas, exceto para o Trecho 03 que foi inferior à campanha de verão. Os valores elevados para a campanha de inverno são devido ao aumento da velocidade e diminuição da profundidade. De acordo com Sperling (2014) cursos de água velozes e rasos tendem a apresentar maiores valores do coeficiente de reaeração $\left(\mathrm{K}_{2}\right)$ o que facilita a mistura no perfil transversal devido à turbulência da água na superfície. Corrêa \& Araújo (2015) também encontraram valores elevados do coeficiente de reaeração utilizando a equação de Owens et al.
(1964). Segundo os autores esses valores foram elevados em função do material que compõe o canal assim como as características hidráulicas.

Os coeficientes de remoção de $\mathrm{DBO}_{5}$ foram calibrados para os cinco trechos utilizando a ferramenta solver do Excel buscando pela maximização do coeficiente de NSE.

$\mathrm{Na}$ tabela 5 são apresentados os valores obtidos do coeficiente de NSE do processo de calibração para a variável $\mathrm{DBO}_{5}$ e $\mathrm{OD}$, nas diferentes campanhas.

Tabela 5 - Coeficiente de Nash- Sutcliffe (NSE) para a calibração da modelagem da qualidade da água.

\begin{tabular}{l|c|c|c} 
Campanha de & \multicolumn{4}{|c}{ Coeficiente de Nash-Sutcliffe (NSE) } \\
\cline { 2 - 4 } Monitoramento & DBO & OD & Média \\
\hline Verão & 0,28 & 0,60 & 0,44 \\
\hline Outono & 0,53 & 0,94 & 0,74 \\
\hline Inverno & 0,43 & 0,88 & 0,66 \\
\hline
\end{tabular}

O coeficiente de NSE varia entre $-\infty$ a 1 . Valores de NSE iguais a 1 indica o ajuste perfeito, valores de NSE superiores a 0,75 indicam que o desempenho do modelo é adequado e valores de NSE entre 0,36 a 0,75 é considerado aceitável (Lopes et al., 2014).

Analisando os valores do coeficiente de NSE para a DBO observa-se que para a campanha de verão o valor encontrado foi inferior a 0,36 , enquanto que nas demais campanhas, os valores foram entre 0,36 e 0,75 o que indica um desempenho adequado.

Para o parâmetro OD, na campanha de verão, o coeficiente de NSE foi igual a 0,60 indicando um ajuste aceitável. Nas demais campanhas o desempenho é adequado, tendo em vista que os valores foram superiores a 0,75. Entretanto, ao considerar o coeficiente médio de NSE, para todas as campanhas, o modelo enquadra-se na faixa de aceitável.

Na Tabela 6 são apresentados os valores dos coeficientes de remoção de $\mathrm{DBO}_{5}$, após a calibração do coeficiente de eficiência de NSE.O coeficiente de decomposição $\left(\mathrm{K}_{\mathrm{d}}\right)$ do Trecho 01, Trecho 02 e Trecho 03 das campanhas de verão e inverno foram superiores ao coeficiente de desoxigenação $\left(\mathrm{K}_{1}\right)$. Já na campanha de inverno essa condição ocorreu em todos os trechos.

Tabela 6 - Coeficiente de remoção de $\mathrm{DBO}_{5}$ calibrados para cada trecho de modelagem.

\begin{tabular}{c|c|c|c|c|c|c|c|c|c}
\hline \multicolumn{9}{c}{ Valores calibrados dos coeficientes de remoção de DBO5 } \\
\hline $\begin{array}{c}\text { Identificação do } \\
\text { Trecho }\end{array}$ & \multicolumn{3}{|c|}{ Verão } & \multicolumn{3}{c}{ Outono } & \multicolumn{3}{c}{ Inverno } \\
\cline { 2 - 11 } & $\mathbf{K}_{\mathbf{1}}\left(\mathbf{d}^{\mathbf{- 1}}\right)$ & $\mathbf{K}_{\mathbf{d}}\left(\mathbf{d}^{-\mathbf{1}}\right)$ & $\mathbf{K}_{\mathbf{s}}\left(\mathbf{d}^{-\mathbf{1}}\right)$ & $\mathbf{K}_{\mathbf{1}}\left(\mathbf{d}^{-\mathbf{1}}\right)$ & $\mathbf{K}_{\mathbf{d}}\left(\mathbf{d}^{\mathbf{- 1}}\right)$ & $\mathbf{K}_{\mathbf{s}}\left(\mathbf{d}^{-\mathbf{1}}\right)$ & $\mathbf{K}_{\mathbf{1}}\left(\mathbf{d}^{-\mathbf{1}}\right)$ & $\mathbf{K}_{\mathbf{d}}\left(\mathbf{d}^{-\mathbf{1}}\right)$ & $\mathbf{K}_{\mathbf{s}}\left(\mathbf{d}^{-\mathbf{1}}\right)$ \\
\hline Trecho 01 & 0,08 & 0,95 & 0,05 & 0,42 & 0,61 & 0,16 & 0,15 & 3,00 & 0,35 \\
\hline Trecho 02 & 0,15 & 1,27 & 0,28 & 0,45 & 0,78 & 0,35 & 0,45 & 1,89 & 0,35 \\
\hline Trecho 03 & 0,14 & 3,00 & 0,35 & 0,45 & 1,49 & 0,35 & 0,11 & 3,00 & 0,35 \\
\hline Trecho 04 & 0,45 & 0,08 & 0,05 & 0,44 & 0,15 & 0,90 & 0,08 & 0,72 & 0,05 \\
\hline Trecho 05 & 0,45 & 0,08 & 0,05 & 0,44 & 0,36 & 0,35 & 0,08 & 0,76 & 0,05 \\
\hline
\end{tabular}


Corrêa \& Araújo (2015) encontraram valores para o coeficiente de decomposição $\left(\mathrm{K}_{\mathrm{d}}\right)$ maiores que o coeficiente de desoxigenação $\left(K_{1}\right)$ no Córrego do Limoeiro, atribuíram que tais características são de corpos hídricos com fenômenos de sedimentação de matéria orgânica, sendo que a remoção da matéria orgânica se dá pelo lodo de fundo.

Segundo Sperling (2014) essas condições ocorre, geralmente, em corpos hídricos mais rasos, pois se tem um menor volume de líquido por unidade de área. Já Teodoro et al. (2013) encontraram valores iguais ou muito parecidos para esses coeficientes, sendo que essas condições ocorrem, normalmente, em rios de águas limpas e com profundidades médias. Portanto, com base neste contexto, infere-se que

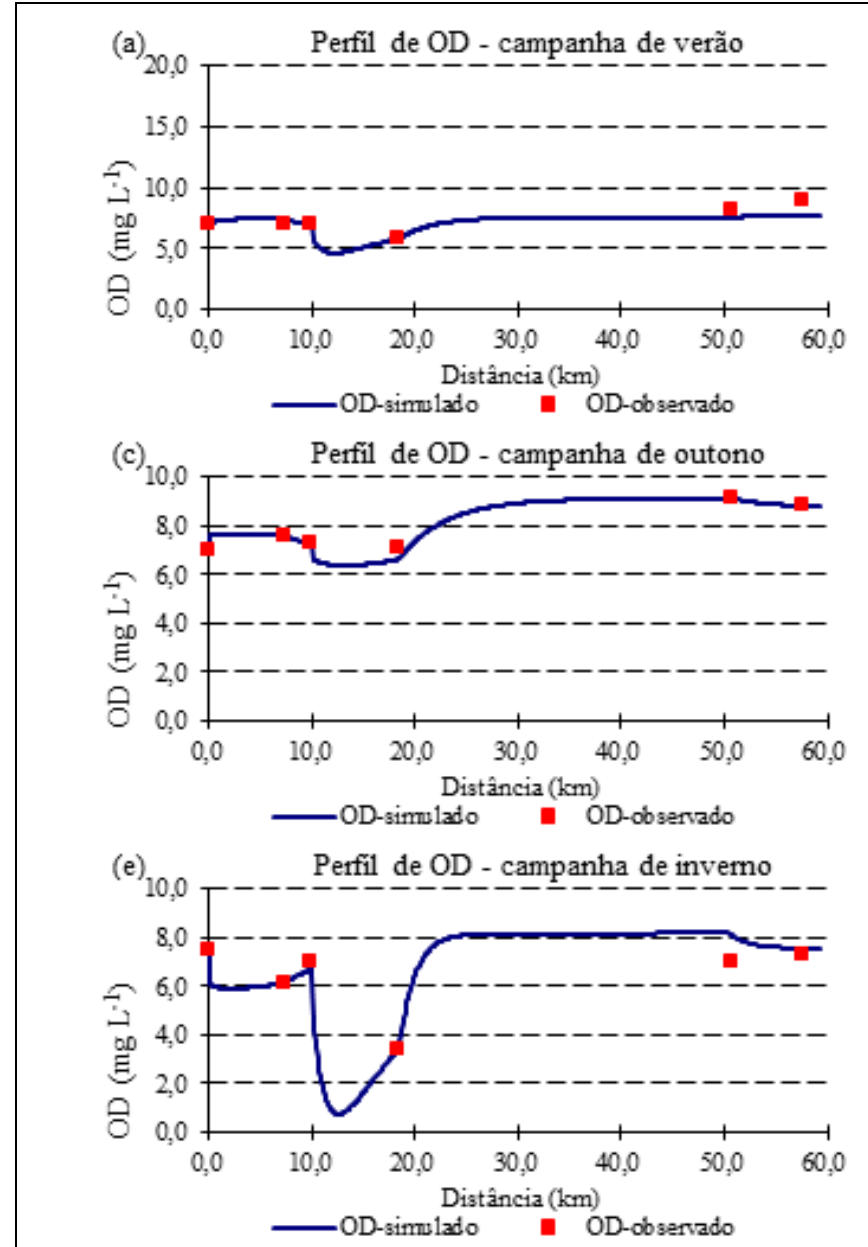

o Trecho 04 e Trecho 05, na campanha de verão, referem-se a zonas de águas limpas. Já na campanha de inverno infere-se que ocorre a sedimentação da matéria orgânica, devido à redução da velocidade do curso de água.

\section{Avaliação da Capacidade de Autodepuração do Rio Ligeiro}

A avaliação da capacidade de autodepuração frente ao lançamento de cargas poluidoras em um corpo hídrico deve ser analisada com muita cautela, pois a análise e interpretação dos resultados equivocadas pode comprometer os usos preponderantes. A capacidade de autodepuração do Rio Ligeiro foi realizada no modelo QUAL-UFMG para o parâmetro OD e $\mathrm{DBO}_{5}$, sendo que os resultados são apresentados na figura 4.

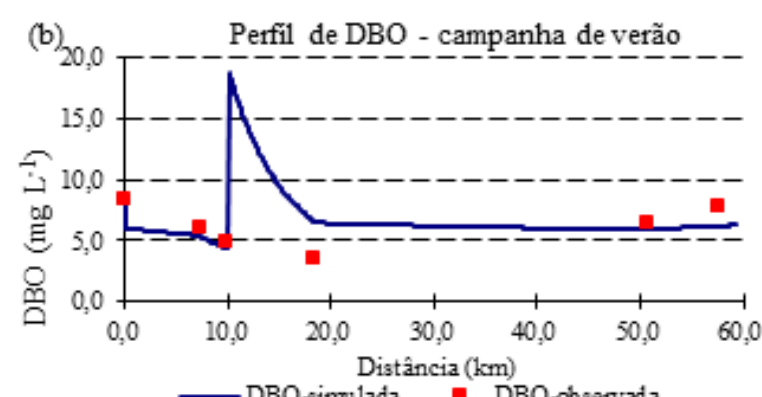

- DBO-simvlada a DBO-observada

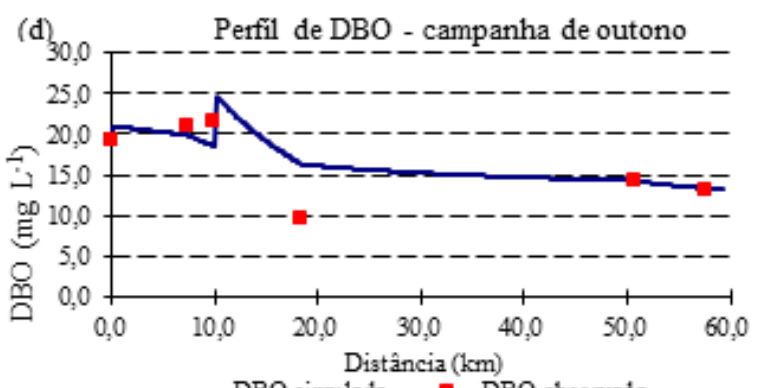

- DBO-simvlada D DBO-observada

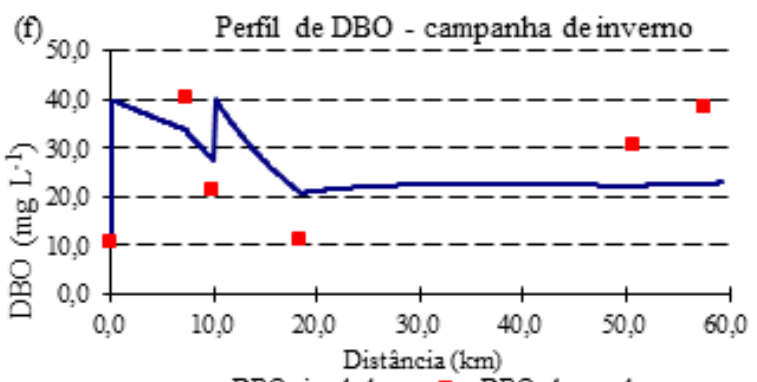

-DBO-simvlada a DBO-observada

Figura 4 - Perfis das concentrações de $\mathrm{DBO}_{5}$ e OD simulados no modelo QUAL-UFMG.

$\mathrm{Na}$ campanha de verão os valores da concentração de OD, Figura 4(a), foram superiores a 7,00 $\mathrm{mgL}^{1}$ no Trecho 01 e Trecho 02, com valores muito próximos da saturação. Após o lançamento pontual de efluentes da ETE da SANEPAR e das atividades industriais, ocorre a depleção do OD atingindo valor mínimo de 4,62 $\mathrm{mgL}^{-1}$. Contudo no final desse trecho, os valores foram superiores ao limite estabelecido na Resolução CONAMA no 357/2005, 5,00 mgL1, apresentando tendência de elevação até a confluência com o Rio Chopim.

$\mathrm{Na}$ campanha de verão, $93,6 \%$ do trecho modelado para o OD atendeu ao limite estabelecido na Resolução CONAMA $\mathrm{n}^{\mathrm{o}}$ 357/2005. O coeficiente NSE calculado foi de 
0,60 indicando um ajuste aceitável. Cabe destacar que os valores simulados foram inferiores aos observados.

Para o parâmetro $\mathrm{DBO}_{5}$, campanha de verão, Figura 4(b), os resultados das análises laboratoriais foram elevados desde a nascente com tendência de decaimento. Na modelagem, os valores simulados foram muito próximos aos observados nos primeiros $10 \mathrm{~km}$, atendendo em parte o limite estabelecido na Resolução CONAMA no 357/2005, 5,00 mgL-1. Após o lançamento de efluentes a $\mathrm{DBO}_{5}$ atinge a concentração máxima, $18,70 \mathrm{mgL}^{-1}$, reduzindo no final desse trecho e mantendo valores praticamente constante até o exutório. Em 3,40\% do trecho modelado a $\mathrm{DBO}_{5}$ atendeu ao limite estabelecido na legislação supracitada. O coeficiente de NSE foi de 0,28, portanto a modelagem da $\mathrm{DBO}_{5}$ não apresentou ajuste aceitável, havendo discrepância entre os dados simulados e os observados, principalmente após os lançamentos pontuais de efluentes.

Na campanha de outono a concentração de OD, Figura 4(c), foi superior a $5,00 \mathrm{mgL}^{-1} \mathrm{em}$ todo o trecho modelado. Na área urbana, Trecho 02, observa-se o declínio de OD, sendo que no início do Trecho 03, após o lançamento de efluentes observa-se maior depleção do OD, atingindo valor mínimo de $6,36 \mathrm{mgL}^{-1}$. No Trecho 04 o teor de OD eleva-se atingindo valores de $9,12 \mathrm{mgL}^{-1}$. No Trecho 05 ocorre novamente a depleção do OD. O coeficiente de NSE foi igual a 0,94 , indicando um bom ajuste entre os dados observados e simulados.

Na modelagem da $\mathrm{DBO}_{5}$ para a campanha de outono os valores simulados foram superiores a 13,20 $\mathrm{mgL}^{-1}$, Figura 4(d), não atendendo ao limite estabelecido na legislação vigente. No Trecho 03 a $\mathrm{DBO}_{5}$ apresentou a maior concentração, $24,70 \mathrm{mgL}^{-1}$, e reduzindo até o fim desse trecho. O coeficiente de NSE nessa campanha foi de 0,53, ajuste aceitável do modelo. Verifica-se que no final Trecho 03 temse um ponto discrepante entre os valores observados e os simulados. Contudo, esse valor observado não atende aos padrões de qualidade, 9,60 $\mathrm{mgL}^{-1}$, que corresponde a menor concentração registrada nessa campanha de monitoramento. Ressalta-se que a campanha de outono se refere à de maior vazão neste estudo.

$\mathrm{Na}$ campanha de inverno a concentração de OD, Figura 4 (e), no início do trecho da modelagem foi igual a $7,50 \mathrm{mgL}^{-1}$ e reduziu até o final do Trecho 01. No Trecho 02 observa-se que ocorreu a elevação da concentração do OD. No Trecho 03 devido ao lançamento pontual de efluentes o teor de OD atinge valor igual a 0,77 $\mathrm{mgL}^{-1}$, e eleva-se, novamente, a valores em torno de $8,00 \mathrm{mgL}^{-1}$ no Trecho 04 . No Trecho 05 os valores decaem atingindo valores em torno de 7,50 $\mathrm{mgL}^{-1}$. A porcentagem da extensão do trecho que atende a Resolução do CONAMA no $357 / 2005$ é de $84,8 \%$, sendo que o não atendimento ocorre inteiramente no Trecho 03 . O coeficiente de NSE para o OD foi de 0,89 indicando um bom ajuste dos dados. Cabe destacar que no fim do Trecho 04 o valor simulado foi superior ao observado, no entanto, ambos acima de $6,00 \mathrm{mgL}^{-1}$.

$\mathrm{O}$ perfil de $\mathrm{DBO}_{5}$ modelado na campanha de inverno, figura 4 (f), apresentou teores acima do limite imposto na Resolução CONAMA $\mathrm{n}^{\text {o }}$ $357 / 2005$ em todo o percurso modelado. No trecho localizado na área urbana, Trecho 01, os valores foram elevados com tendência de declínio ao final do Trecho 02 . No Trecho 03 os valores simulados atingiram a máxima concentração, 40,00 $\mathrm{mgL}^{-1}$. Após o Trecho 03 os teores de $\mathrm{DBO}_{5}$ permaneceram entre $20,00 \mathrm{mgL}^{-1}$ e $25,00 \mathrm{mgL}^{-1}$. O coeficiente de NSE calculado foi 0,43 , modelo com ajuste aceitável. Contudo, analisando os dados observados e simulados verifica-se que os valores apresentaram discrepância.

Os resultados da modelagem de OD podem ser considerados satisfatórios, pois os valores simulados foram muito próximos das condições reais. Diante desse resultado, infere-se que fotossíntese, respiração algal e nitrificação são variáveis de segunda ordem na modelagem da qualidade da água do Rio Ligeiro.

Em contrapartida para a $\mathrm{DBO}_{5}$ a modelagem apresentou valores discrepantes com as condições reais. A discrepância entre os dados observados e modelados de $\mathrm{DBO}_{5}$ podem estar relacionados, principalmente, com a não identificação e mensuração dos pontos de lançamentos de efluentes, clandestinos ou não, assim como dos afluentes do Rio Ligeiro. Contudo, cabe destacar que a $\mathrm{DBO}_{5}$ apresentou valores medidos e estimados no intervalo entre 3,60 $\mathrm{mgL}^{-1}$ até 40,20 $\mathrm{mgL}^{-1}$, sendo que em quase toda a extensão, em ambas as campanhas, a concentração de $\mathrm{DBO}_{5}$ apresentou-se acima do limite estabelecido na Resolução do CONAMA no 357/2005. Com base nos resultados de $\mathrm{DBO}_{5}$ o Rio Ligeiro enquadra-se na classe 4. Portanto, 
a qualidade da água do Rio Ligeiro encontra-se degradada desde a nascente.

Salla et al. (2013) modelaram a DBO e o OD para o Rio Jordão, e chegaram a resultados de ajustes para DBO semelhantes a este estudo, sendo que em todo o trecho os valores de DBO foram acima do limite preconizado na legislação ambiental vigente.

Os teores de OD apresentaram depleção em todas as campanhas, principalmente após o perímetro urbano e os lançamentos pontuais de efluentes. Contudo, em menos de $15 \mathrm{~km}$ de percurso os teores de OD chegam a valores superiores aos registrados a montante dos lançamentos de efluentes. Em contrapartida, os usos da água, neste trecho de equilíbrio ambiental, devem ser evitados, seja captação e/ou lançamento.

Diante dos resultados supõe-se que o Rio Ligeiro apresenta elevada capacidade de reaeração natural, sendo que tais condições estão relacionadas com as condições hidráulicas do Rio Ligeiro, velocidade e profundidade, quedas de água assim como o material que compõem o fundo do canal, pois nas coletas dos dados observou-se que o material de fundo proporciona maior turbulência das águas o que permite maior transferência de oxigênio para a massa líquida.

Analisando os dados modelados das três campanhas é possível constatar que a vazão apresenta significativa interferência na capacidade de autodepuração, sendo que na campanha de menor vazão, campanha de inverno, foi a que apresentou situações críticas. Enquanto na campanha de maior vazão, campanha de outono, apresentou as melhores condições de qualidade, tendo em vista que a concentração de OD foi superior a $5,00 \mathrm{mg} \mathrm{L}^{-1}$, determinação da Resolução do CONAMAn ${ }^{\circ}$ $357 / 2005$, em todo o percurso do Rio Ligeiro. Conclui-se que as fontes de poluição difusas apresentam menor interferência na qualidade da água, indicando, portanto, que as cargas orgânicas oriundas das fontes pontuais apresentam significativa interferência na qualidade das águas.

Em termos de OD o Rio Ligeiro apresenta capacidade de autodepuração. Já para a $\mathrm{DBO}_{5} \mathrm{O}$ corpo hídrico encontra-se degradado desde a nascente. Ressalta-se que, com base nesse estudo, a capacidade de autodepuração do Rio Ligeiro está intimamente relacionada com as condições de vazão.

\section{CONCLUSÕES}

Este trabalho teve como objetivo principal a aplicação da modelagem de qualidade da água para a avaliação da capacidade de autodepuração assim como a verificação de atendimento aos padrões de qualidade estabelecidos na Resolução CONAMA no 357/2005. O monitoramento da qualidade da água compreendeu as diferentes estações, sendo que as coletas dos dados e amostras foram realizadas considerando os eventos de precipitação de forma a abranger vazões mínimas e máximas.

$\mathrm{Na}$ modelagem da qualidade da água utilizando o modelo QUAL-UFMG, a calibração do OD apresentou um bom ajuste entre dos dados modelados com os obtidos em campo, com coeficiente de NSE superior 0,60. Em contrapartida, a $\mathrm{DBO}_{5}$, de maneira geral, não apresentou bons ajustes. A explicação para esses resultados está no fato do desconhecimento das condições reais de lançamento de efluentes, clandestinos ou não, assim como dos dados e parâmetros dos afluentes do Rio Ligeiro.

Em todas as campanhas que se aplicou o modelo QUAL-UFMG observou-se que após a área urbana e os lançamentos pontuais de efluentes foi o trecho onde as condições de quali-dade apresentaram condições críticas, declínio da concentração de OD e elevação da $\mathrm{DBO}_{5}$.

Na campanha de menor vazão, campanha de inverno foi a qual o Rio Ligeiro apresenta as piores condições da capacidade de autodepuração, chegando a condições anaeróbias. Já na campanha de maior vazão, campanha de outono, as concentrações de OD atenderam em toda a sua extensão os padrões de qualidade estabelecidos na Resolução

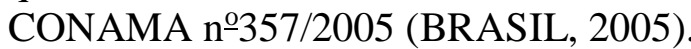

$\mathrm{A} \mathrm{DBO}_{5}$ apresentou valores elevados desde a nascente, apresentando valores dentro dos padrões em apenas $3,40 \%$ da extensão total do trecho modelado na campanha de verão.

A concentração de OD, um dos principais parâmetros para a avaliação da degradação de cursos de água, apresentou valores elevados desde a nascente atingindo valores muito próximos da saturação no último PM. Essas condições indicam que este corpo hídrico apresenta elevada capacidade de reaeração devido às condições hidrológicas.

O modelo QUAL-UFMG foi adequado para a modelagem da qualidade da água do Rio Ligeiro, 
sendo de fácil manuseio e entendimento dos dados de saída.

Este estudo possibilitou o conhecimento da situação atual da qualidade da água do Rio Ligeiro, indicando que este corpo hídrico sofre pressões das atividades antrópicas desde a nascente e que medidas de gestão e controle devem ser implantadas.
Por fim, para trabalhos futuros, recomenda-se a implantação de novos pontos de monitoramento e mensuração de dados e parâmetros das fontes de lançamentos de efluentes, assim como nos afluentes do Rio Ligeiro, com maior frequência de monitoramento. Além disso, a inclusão de outros parâmetros na modelagem da qualidade da água.

\section{AGRADECIMENTOS}

Ao Programa de Pós-Graduação em Engenharia Civil (PPGEC) da Universidade Tecnológica Federal do Paraná, campus Pato Branco, pelo apoio financeiro a pesquisa, e a Coordenação de Aperfeiçoamento de Pessoal de Nível Superior - CAPES e ao Conselho Nacional de Desenvolvimento Científico e Tecnológico - CNPq pela bolsa concedida.

\section{REFERÊNCIAS}

ABNT - Associação Brasileira de Normas Técnicas. NBR 9897/1987 - Planejamento de amostragem de efluentes líquidos e corpos receptores. Rio de Janeiro, ABNT, 1987

BATISTA, D.F. \&Cabral, J.P.B. Modelos matemáticos para avaliação do índice de qualidade de água: uma revisão. ACTA Geográfica, v. 11, n. 25, p. 111-136, 2017.

BENETTI, A \& BIDONE, F.R.A. O meio ambiente e os recursos hídricos. In: TUCCI, C. E. M. (Org.). Hidrologia: ciências e aplicação. 4. ed. Porto Alegre, RS: UFGRS - Faculdade de Agronomia, 2009.

CARVALHO, A.P.; BALDUINO, A.R.; MACIEL, G.F. PICANÇO, A.P. Avaliação da poluição em rios utilizando índices de qualidade da água: um estudo de caso no Ribeirão São João em Porto Nacional - TO. Geociências, v. 35, n. 3, p. 472-484, 2016.

CORREAA, T.S. \& ARAÚJO, R.R. DE. Estudo de autodepuração: o caso do córrego do Limoeiro, Presidente Prudente - SP. Colloquium Exactarum, v. 7, n. 3, p. 48-55, 2015.

COSTA, D.J.L.; TEIXEIRA, D. Aplicação de modelo de autodepuração para avaliação da qualidade da água do Ribeirão do Ouro, Araraquara-SP. Uniara, v. 13, n. 1, p. 49-62, 2010.

FLECK, L.; TAVARES, M.H.F.; EYNG, E. Principais modelos matemáticos de qualidade da água e suas aplicações: uma revisão. Revista Eletrônica e Cientifica Inovação e Tecnologia, Medianeira, v. 1, n. 7, p. 47-62, 2013

HEINZ, O.L.; LUZ, E.; AMORIM, J.S.; RONCATI, R.; LOSS, E. Avaliação do índice de qualidade da água na microbacia do Rio Ligeiro - Pato Branco sob a ocupação urbana. SIMPÓSIO DE TECNOLOGIA EM QUÍMICA; SEMANA ACADÊMICA DE QUÍMICA, 3, 14., 2016, Pato Branco. Anais eletrônicos...Pato Branco: SIMTEQ, 2016. Disp. em: <http://anais.trendcongresso.com.br/simteq2016/papers/>. Acessado em: 18fev2018.

IBGE - INSTITUTO BRASILEIRO DE GEOGRAFIA E ESTATÍSTICA, Cidades, 2017. Disponível em: <http://cidades.ibge.gov.br/v3/cidades/municipio/4118501>. Acessado em: 18 fev2018.

IAPAR - Instituto Agroclimático do Paraná. Médias históricas, 2017. Disp. em: <http://www.iapar.br/arquivos/Image/mo nitoramento/Medias_Historicas/Pato_Branco.htm>Acessado em: 18 fev2018.

JABUR, A.S. Alterações hidrológicas decorrentes de mudança do uso e ocupação do solo na bacia hidrográfica do alto do rio Ligeiro, Pato Branco - PR. Curitiba, 2010. 178 p. Tese (Doutorado em Engenharia Florestal) - Setor de Ciências Agrárias, Universidade Federal do Paraná.

JABUR, A.S. \& RIZZI, N.E. Estimativas da vazão máxima e capacidade de saturação hídrica da bacia hidrográfica do alto do Rio Ligeiro em Pato Branco, PR. Floresta, v. 41, n. 4, p. 833846, 2011
LOPES, F.B.; BARBOSA, C.C.F.; NOVO, E.M.L.M.; ANDRADE, E.M.; CHAVES, L.C.G. Modelagem da qualidade das águas a partir de sensoriamento remoto. Revista Brasileira de Engenharia Agrícola Ambiental, v. 18, p. 13-19, 2014

MORUZZI, R.B.; CONCEIÇÃO, F.T.; SARDINHA, D.S.; HONDA, F.P.; NAVARRO, G.R.B. Avaliação de cargas difusas e simulação de autodepuração no Córrego da Água Branca, Itirapina (SP). Geociências, v. 31, n. 3, p. 447-458, 2012.

OLIVEIRA FILHO, A.A. \& LIMA NETO, I. E.Modelagem da qualidade da água do rio Poti em Teresina ( PI ). Engenharia Sanitária Ambiental, p. 1-12, 2017.

PARANÁ. Outorgas de lançamentos de efluentes, 2017. Disp. em:<http://www.aguasparana.pr.gov.br/modules/conteudo/con teudo.php?conteudo=79>. Acessado em: 18 fev2018.

PIZATTO, E. Avaliação da qualidade da água do rio Ligeiro por meio de análises físico-quimícas e microbiológicas. Pato Branco, 2011, 58 p. Trabalho (Conclusão de Curso) Bacharelado e Licenciatura em Química), Universidade Tecnológica Federal do Paraná. Pato Branco.

RODRIGUES, D.B.B.; OLIVEIRA, P.T.S.; CAVAZZANA, G.; IDE, C.N. Análise da qualidade da água de Rio Anhanduí - MS utilizando o modelo QUAL-UFMG.SIMPÓSIO BRASILEIRO DE RECURSOS HÍDRICOS, 18., 2009, Campo Grande, MS. Anais... Campo Grande, MS: ABRH, 2009. Disp. em: <https://www.abrh.org.br/SGCv3/index.php?

$\mathrm{PUB}=3 \& \mathrm{ID}=110 \& \mathrm{SUMARIO}=2353 \& \mathrm{ST}=$ analise_da_quali dade_da_agua_de_rio_anhandui_ms_utilizando_o_modelo_qu al_ufmg>.

SALLA, M.R.; PEREIRA, C.E.; ALAMY FILHO, J.E.; PAULA, M.M. DE.; PINHEIRO, A.M. Estudo da autodepuração do Rio Jordão, localizado na bacia hidrográfica do Rio Dourados. Engenharia Sanitária Ambiental, v. 18, n. 2, p. 105-114, 2013.

SPERLING, M. Estudos e modelagem da qualidade da água de rios. 2. ed. Belo Horizonte, MG: UFMG, 588 p., 2014.

SUNDARAY, S.K.; PANDA, U.C.; NAYAK, B.B.; BHATA, D. Multivariate statistical techniques for the evaluation of spatial and temporal variations in water quality of the Mahanadi river - estuarine system (India ) - a case study. Environmental Geochemistry and Health, v. 28, p. 317-330, 2006.

TABALIPA, N. L.\& FIORI, A. P. Influência da vegetação na estabilidade de taludes na bacia do Rio Ligeiro (PR). Geociências, v. 27, n. 3, p. 387-399, 2008a.

TABALIPA, N. L.\& FIORI, A. P. Influência do vento na estabilidade dos taludes da bacia do rio ligeiro, município de Pato Branco (PR). Caminhos da Geografia, v. 9, n. 27, p. 8298, 2008b

TABALIPA, N.L.\& FIORI, A.P. Caracterização dos solos da bacia do Rio Ligeiro (PR) na estabilidade de taludes. Revista 
Brasileira de Geociências, v. 42, n. 1, p. 11-26, 2012.

TEODORO, A.; IDE, C.N.; RIBEIRO, M.L.; BROCH, S.A.O.; SILVA, J.B. Implementação do conceito capacidade de diluição de efluentes no modelo de qualidade da água QUALUFMG: estudo de caso no Rio Taquarizinho (MS). Engenharia Sanitária Ambiental, v. 18, n. 3, p. 275-288, 2013.

TOMAZONI, J. C. Banco de dados geográficos do município de Pato Branco, 2009.

TOMAZONI, J.C.\& GUIMARÃES, E. Características espectrais das frações humina e ácido húmico da matéria orgânica total dos solos da bacia do rio Passo da Pedra. Revista Brasileira de Geografia Física, v. 8, n. 3, p. 721-735, 2015.
VARGAS, E.H. \& MARQUES, F.S. Análise da autodepuração do curso d' água Pomba Cuê utilizando o modelo Streeter Phelps. Pleiade, v. 9, n. 17, p. 83-92, 2015.

WATTHIER, E.K.; DIAS, C.A.; LOSS, E. RODRIGUES, M.B.; MOREIRA, J. Caracterização e avaliação do índice de qualidade da água da jusante do rio Ligeiro - Pato Branco - PR. Synergismus scyentifica UTFPR, v. 3, n. 4, 2008.

Submetido em 15 de março de 2018 Aceito em 4 de julho de 2019 